\title{
Sustainable Development of Traditional Houseboat: Based on the Research of Primitive Architecture of Li Nationality in Hainan Province
}

\author{
Fuyu Yang ${ }^{1}$
}

\begin{abstract}
Li Nationality is the earliest boong in Hainan Province, their history and cultures are listed in The World's and National Intangible cultural Heritage. Li Nationality's dwellings space and model have their peculiar vantages including the ancient wisdom of sustainable environmental protection and respecting natural world. Li Nationality adopted the idea of building a boat to construct houses and organized their own families before 4000 years ago and the houseboats contained typical characteristics of simple, saving materials and making good use of the old boats. However, with the modern cultures influence of Han Nationality, more Li people is giving up their traditional houseboats. The only reserved village which possesses traditional houseboats is Baizha in the Dongfang City of Hainan Province. Hainan Province government and researchers are trying to protect the related cultures and houseboats style architecture by moving them into the scenic area or introduce more tourists to visit village having houseboats to increase the income of Li Nationality and make them adapt themselves to modern economic society based on reserve traditional life-style. Step 1 is digging historical and cultural information in Li Nationality, their fairy stories, religious faith and folk songs, step 2 is applying all those materials to intangible cultural heritage list and getting enough subsidiary funds from governments, step 3 is organizing researchers and architects to visit village, step 4 is attracting more tourists to visit it, reserving this traditional architecture style based on cyclic economy.
\end{abstract}

Keywords: sustainable development, houseboats, Li Nationality

\section{Introduction}

House is an architecture combined human beings' living customs, cultures, faith and relationships between nature and human. It satisfies the need of survival and protection and reflects thoughts to the natural world. Because of the various climate conditions, building materials and the levels of technology, the housing shapes and forms are different in worldwide. (Zhaolin Song, 1983)In agricultural society ancients of Li Nationality in China built a special house whose shape like an up-side-down boat and people from one family lived together as a distinct characteristics differed from other nationalities. So the inverse houseboat of Li Nationality in Hainan Province has a strong identification. This structure of architecture in the island of Hainan comes from special life circumstances and nature of Li Nationality. Boat is not only an important tool to make living to go fishing on the sea but also a major inspiration to most of ancient Li nationality. (Mingshu Chen, 2004)When the men went fishing floating on the boats for several months, they wanted to leave some real items to their wives lived in the island to 
miss them, the boats became a better choice than other items decomposed easily by the moisture and hot weather. The boat-shape architecture which is like a boat is laid upside-down on the ground and protected their wives and children avoid to expose under the blazing sun and typhoon with the building materials of mud, leaves, woods and thatch. It is considered the efficient ways to find the materials to built a house quickly and not to need a lot of men to help. (Zhen Fu, 1982)However, with the development of economic and times this style of architecture is fade away as a kind of important historical cultures to Li Nationality.

\section{Current Situations}

Current situation of traditional houseboat in Hainan Province is alarmingly. Many evidences have shown that houseboat of Li Nationality as a kind of special architecture style is disappearing. The style of “金” (a Chinese word, means gold. Because the shape and meanings of this word like the roof the house, Hainan People uses this word to symbol a kind of structure.) is the most important characteristics to houseboats. Researchers had traveled and looked for many fishing villages and habitual residence of Li Nationality, only few houseboats are protected because of the development of traveling sight spot, these houseboats will be closed after sunset and no people live in them. The reasons are complex to these houseboats from the life of Li Nationality. One of the important reasons is influences and impacts of Han People's culture. Han People migrated from the mainland to the island of Hainan, communicated with different nationalities and built houses with the style of Han in Island, Li Nationality received this buildings gradually.(compared Picture 1 and Picture 2 as followed) The second reason is that Hainan Province was approved by Chinese governments to build International Tourism Island from 2010 to 2020, this island provided more jobs related to the tourism, it pushes more young people move from the remote mountains of villages to bigger cities hunting a job. The researchers had interviewed more than 500 young men in villages, the results showed that $73.6 \%$ of them expected to stay in big cities and bought a modern department in the future, only less $4 \%$ of them expressed that they would return to their hometowns after earn enough money but build modern-style houses because they had received the the modern and convenient apartments in the towns. Most of them abandoned the traditional life-style, learned mandarin, got more chances of promotion and transferred themselves as city white collars or normal laborers. Houseboats are representing an inconvenient and old living style. Based on these reasons, most of traditional houseboats faded out gradually or a few old people are living in it. However, there is a motto to describe the relationships between people and architecture: it can be seen that architecture represents the people subordinated by the cultures, history and faith differentiated from other people. Easier abandoning yourselves, harder re-seeking for yourselves. 


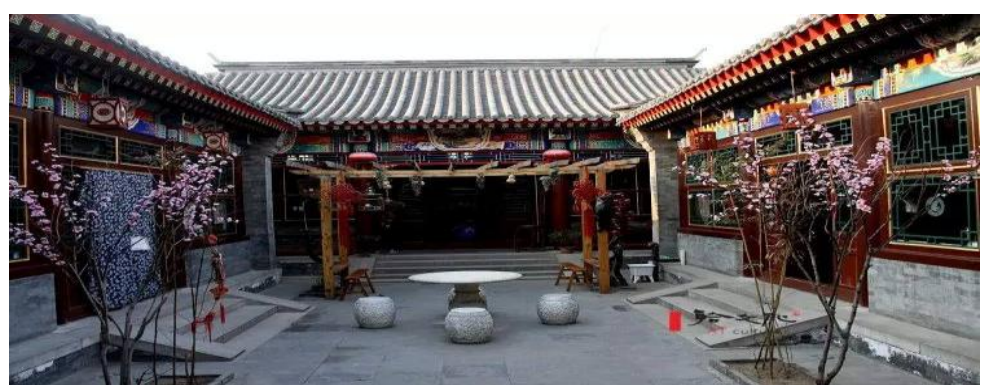

Pic. 1: Han architecture with bricks and tiles

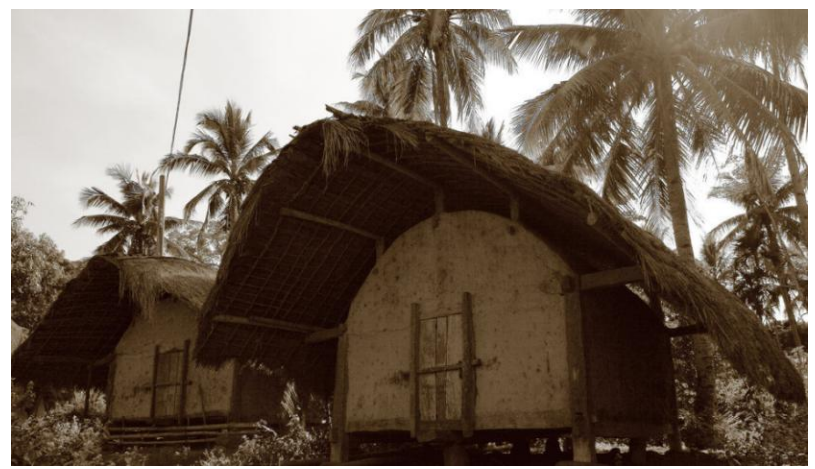

Pic.2: Li Nationality's houseboats with woods, mud and thatches

\section{History}

Houseboats in Hainan Province have their own special value in the history and culture of architecture. In fairy story of Li Nationality, there was a Princess Danya who lived in Li Empire and ever married three husbands died finally, she was considered a woman cursed by God because of her unlucky marriages. The people in Li Empire wanted Li King to execute Princess Danya, Li King thought his daughter was very pitiful and reluctant to execute her and then gave her a boat with enough fresh water and foods, helped his daughter push this boat to the sea. Princess Danya floated on the sea lonely and bravely and stopped besides an island(Hainan Island) finally. There were no enough materials to build a house in short time, Princess Danya had to go fishing in the daytime, and protected herself by up-side-down boats in the night time. (Mingshu Chen, 1993)This is the history story of houseboats in Li Nationality. Houseboats ever played an importance role in the life of Li Nationality in Hainan Province, it is one of the important heritages in the culture of Chinese architecture also. In the long history houseboats accompanied with the life of Li Nationality and had their own special characteristics differed from other houseboats appeared ever in the other regions such as Zhejiang Province in China. (compared between Zhejiang Province houseboats as Picture 3 and Hainan Province houseboats as Picture 4)Zhejiang Province had its different houseboats which are built a small shelter on the boat, fish men or ferry men wouldn't leave their family and lived under the shelter together, they lived on the water and got foods from the lakes and rivers directly, every 3-4 months they would stop their 
boats besides of a city and exchange fishes, lotus roots, lotus seeds and water chestnuts to money to buy salts, cloths and other living materials, hitherto they still keep this living style. However, houseboats in Hainan Province are differentiated from other regions not only the special shape recorded in the history of architecture but also having simple perception of environmental protection from ancient people who adopted limited natural materials and didn't change the basic functions of a boat but solved the living problems from two directions: the boat used in daytime normally and night inversely.

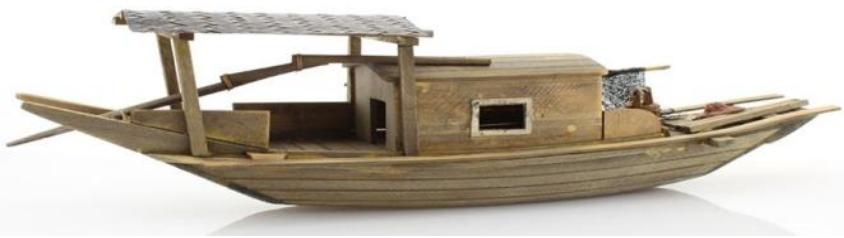

Pic.3: Zhejiang Province houseboats

\section{Pic.4: Hainan Province houseboats}

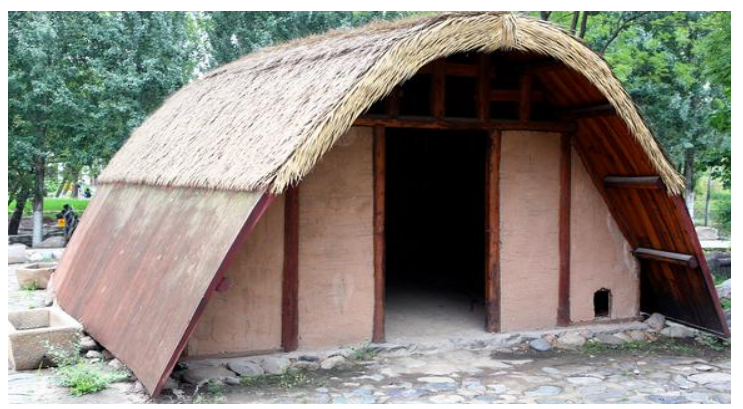

\section{Methods}

Although the opinions of Historical origin about houseboats in Hainan Province are widely divided, from the folk story it in Hainan Province has an obvious difference with others: no windows. (as the compare as Picture 3 and 4)In history the Hainan Island with less population had many ferocious animals attacked people during the night, the strong labour men went fishing for several months, it was impossible that women and children had enough power to fight back to those animals. People in Li nationality found the inspiration from the up-side-down boat: the less amount of entrances to a house, the better. If we calculate the amounts of people in protection based on the theory of ancient military strategy, houseboats' entrances needed only 2-4 people to defend(the amounts of entrances plus one, it will increase 2 people to defend at least). That is also means that after they measured the choices between protecting themselves and putting up with the moisture, hot weather, they chose the former: no windows.

Compared with Han buildings houseboats of Li Nationality have a parenthetical roof, that is the key and typical characteristics because parenthetical roof has bigger space than Han houses inside. It seems that although they couldn't choose more windows because of protection, they still tried many ways that brought more spaces and cool air in the 
houseboat as possible as made themselves feel comfortable.

The initial reason for building houseboats is that ancient people of Li Nationality earned them living by fishing, once they met storms they had to come back to the land. They did not want to waste time and their energy to build an immovable house, they preferred to turning the bottom of boats over as a temporary but permanent shape house. To protect boat they cut grass or knitted the matting to cover it, Li Nationality made use of least resources from the outside nature and surroundings. And they could move their living tools and houses whenever and wherever possibly. When they left land and come back to the oceans they had a least environmentally damaging activities to the surroundings. Once they come back from the ocean they did not worry that they had to keep the same path last time to go home because where there was a boat, where there was a house. This kind of flexibility is another superior to the Han buildings. However, when sometimes men had to leave their wives and children on the island for a long time, they left the old boasts to them. Although the boats decomposed by the moisture and strong sunshine, the shape of boasts was remained to build houses continuously. Afterwards the houseboats' building materials are leaves, mud, woods and thatches which are found and collected easily in the natural world. Women and children were the main labors on island during the period of fishing to men, they couldn't go far away to find other building materials and had no enough physical strength to cut trees down and deliver them back village. Utilizing keels of old boats covered with knitting thatches and mud is an efficient way, comparatively fixed house with shape of boats occurred in Hainan Island.

There are many vantages of traditional houseboats of Li Nationality in Hainan Proinve. This style of buildings not only protects people of Li Nationality to storms and animals but also guarantee them to use least materials from surroundings and natures to build their house. The other vantage is the ganlan-style architectures tied by skins of splints have a strong toughness and elasticity to resist storms. The arched roof has a bigger space than the Han buildings and apertures between floor and ground make the houseboats draughty well considered the weather conditions. (as illustrated Figure I)(Jie Huang, 1997:33)

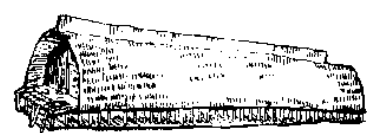

outside view
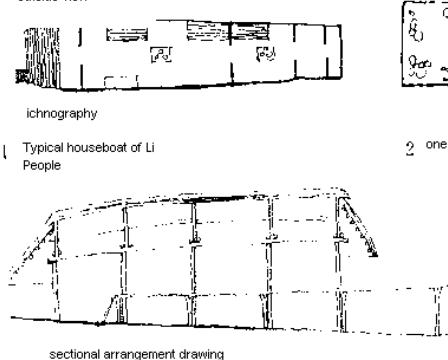

Figure 1.Traditional houseboats of Li Nationality
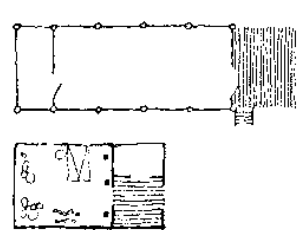

2 one room dwelling

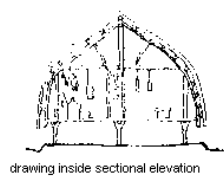

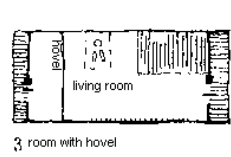
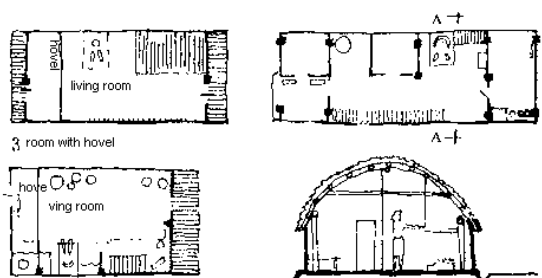

4 seperate room
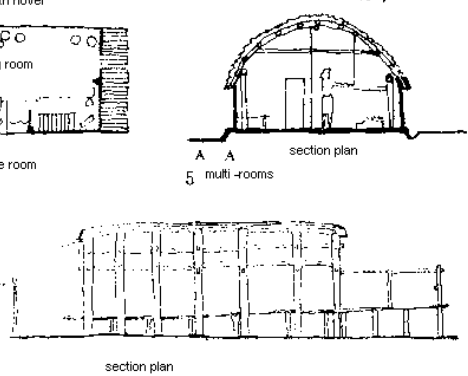
Moist air and snakes or other animals will be kept out with the ganlan-styled of Li Nationality. Their houseboats are suitable to the local climates and surroundings.

Economically, houseboats use least materials from surroundings and nature and all of the building materials are receivable and recyclable, this boat-shape architecture is considered the sustainable development and environmental protection ideas from ancient people. Socially, in a bigger houseboat several generations lived together, young people could take care of older men conveniently. When many bigger houseboats built together, people of Li Nationality can resist animals and enemies and provide more chances for the young girls and boys to marry (Figure II)(Jie Huang,1997:35).
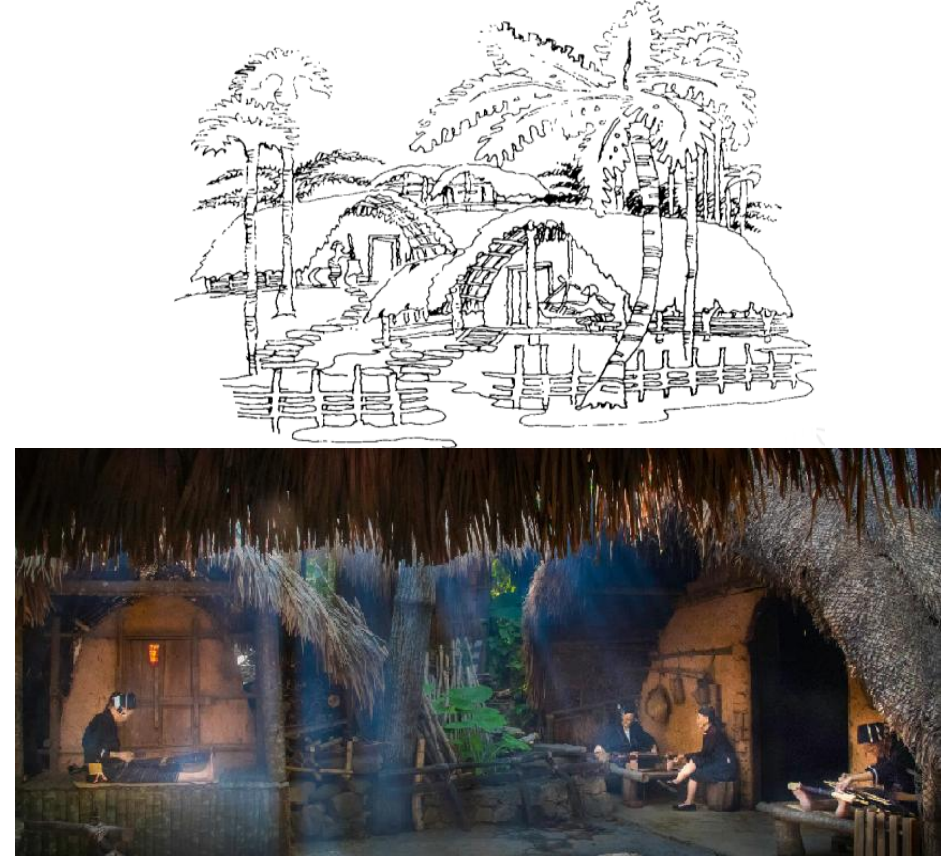

Figure 2 Houseboats collecting together

To protect history and cultures of Li Nationality, more researchers and professors allied local governments are devoting themselves to houseboats and other historical architectures and cultures. For example, Baizha village is the only one reserved traditional houseboats, many researchers visited there, by different researching angle such as cultures, history, tourism, economy and so on they design a pathway to solve the problems of Li Nationality.

Step 1 is digging historical and cultural information in Li Nationality, their fairy stories, religious faith and folk songs. This job can help Li Nationality protect their own history and culture as possible and some unbeknown information, exacting those information enhances the possibilities of arts and tourism industrial innovation further, it is believed that more tourism products manufacturing enterprises are trying to print the totems of Li Nationality on the T-shirts, cups, bags and have got a better revenues. Those totems are attracting more tourists visit villages of Li Nationality, and enterprises will pay some fees for totems. These methods increase the incomes and participation of local villagers 
to protect their own culture and history in active.

step 2 is applying all those materials to intangible cultural heritage list and getting enough subsidiary funds from governments. Local researchers had finish the collections of history and cultures and record them into the heritage lists and applied those for Intangible Heritage List successfully. It is because these measures are successful that local governments begin to emphasize the protection further and allocate the special funds to support the researching works and help villagers to build or repair their houseboats.

step 3 is organizing researchers and architects to visit village. The local researchers invite more researchers, architects and photographers to visit Li villages, those experts share their experiences on the web and build up an excellent reputation. This method helps Li villages attract not only more tourists but professionals who have different professional angles to dig cultural information and redesign some totems, decorations inside and shape outside of the houseboats to modern arts.(as shown Picture 5, Picture 6 and Picture 7) Those professionals are helping to improve the abilities of designing, aesthetic, combination between ancient technology and modern business in Li Nationality. More populations in Li Nationality are lifting themselves from poverty and infusing them into the modern society well. The local governments organize exhibitions annually to show arts, products and achievement of Li's women to increase the household income for promoting social status of women further.
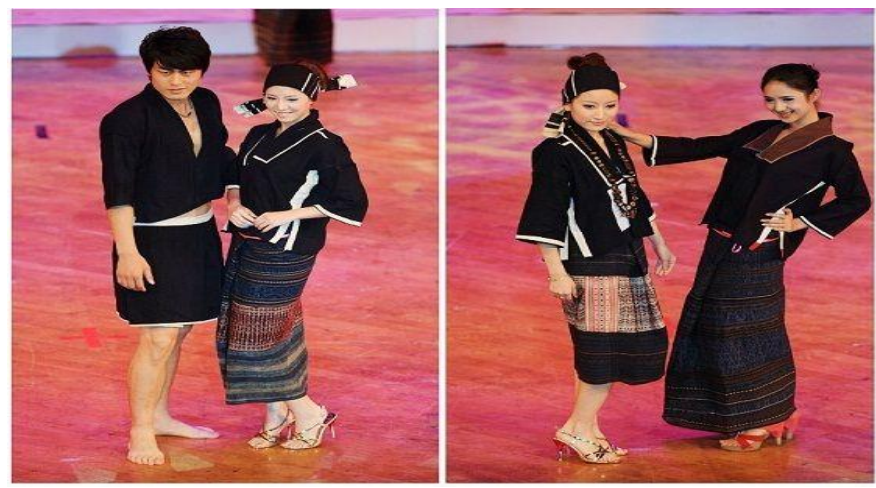

Pic 5: Li Brocades with totems

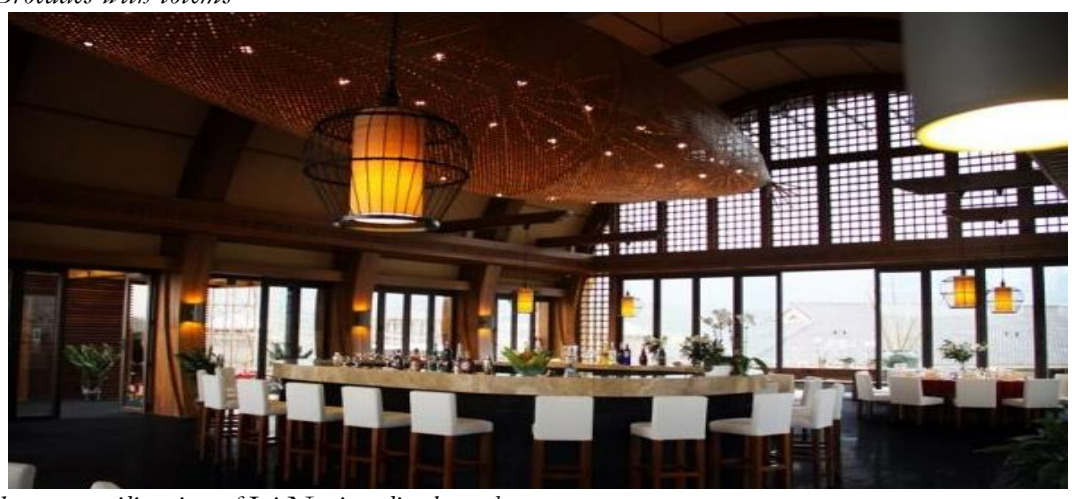

Pic 6: modern-art utilization of Li Nationality houseboats 


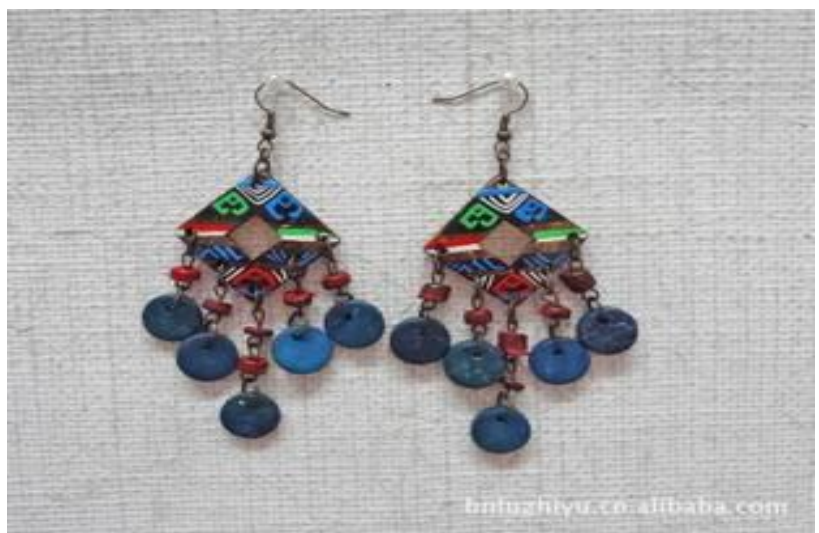

Pic 7: Modern arts of women accessories made by coconut shell

Step 4 is attracting more tourists to visit villages, reserving this traditional architecture style based on cyclic economy. The local researchers and governments had design a sustainable system in the field of cycle economy and mechanisms of reserving history and cultures. In this system, synergy related houseboats is considered efficiently, for example, by building Think Tank allied researchers and professionals provided most of innovative ideas and methods of reserving. Another example, Baizha village which has houseboats during all natural villages in Hainan Province established an observing system to tourists who probably are interests in the history and cultures and consume in cultural products. By analyzing the tourism data researchers can improve the surroundings of tourism and promote the experiences of tourists.(as illustrated Figure III)

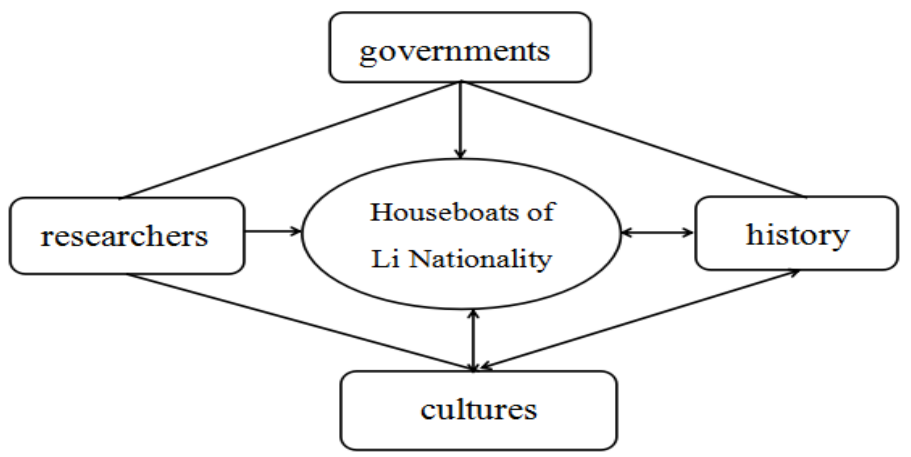

Figure 3: synergy of reserving houseboats in Hainan Province

\section{Conclusions}

The houseboats are disappearing from the life of Li Nationality because of culture influence although they have many obvious vantages. How to protect this style of architecture and culture is a difficult question. Culture has the characteristics of diversities, one style of architecture should not replace the others. It needs the government or organizations of cultural relics preservation to formulate to increase influences in society about traditional and special houseboats of Li Nationality further. 
To protect this type of special architecture and cultures of Li Nationality, the researchers and local governments should do:

Increasing the cultural effects among Li people further. Although many young people moved their families from remote mountains to bigger cities, they will come back annually during the periods of worship ceremonies such as Junpo Festival (commemorating Madam. Xian,Li people, A.D.552-601, a famous female general to protect local people in Hainan Island) or Sanyuesan Festival (important festival, The List of World Intangible Cultural Heritage). Cultures and relationships of families in $\mathrm{Li}$ Nationality are attracting more culture scholars and academic folklorists to visit Hainan Province, helping Li Nationality to sort out cultural information and record them. These activities enhance the recognition of cultural identity and perception of affiliations to $\mathrm{Li}$ people.

Decreasing the poverty population of $\mathrm{Li}$ people further. Houseboats have exclusive attractions not only to tourists but Li Nationality because it represents their families and important parts of their cultures. Researchers with local Li's women are developing modern houseboats souvenirs such as mini houseboats used by the materials of thatches and ropes, these mechanisms are considered that they can increase income for families. And more researchers are explaining the meanings of Li's totems and exploit those totems to enhance the Li's cultural charming for tourists.

Combination between Li's houseboats, cultures and arts and modern arts and architectures. Li's houseboats including the important cultural information and representing cultural labels contain national wisdom and family faith of natural world. Protecting houseboats of Li Nationality it is important that old cultures can be combined well into the new and modern arts and cultures. Researchers and local governments need to dig cultural meanings and information of houseboats of Li Nationality, and make this old architecture find out its own sustainable development pathway in modern society.

\section{References}

[1]Zhaolin Song, Jiafang Li, Yaoxi Du. Social history of Chinese primitive society. [M]. Peking: Cultural Relic of Press, 1983.

[2]Mingshu Chen. Memo Pad in Island of Hainan.[M]. A Series of Books in Hainan.2004.

[3]Zhen Fu, Hai'ou Su. Li Nationality Tales. [M]. Guangzhou: Huacheng Press, 1982.

[4]Jje Huang, Yu Wang. The Culture of Houseboats: The Traditional Residence of Li Nationality in Hainan. [J]. NEW ARCHITECTURE.1997(4):32-35

[5]Mingshu Chen. Hainan Island Geographica.[M]. Publisher:anonymity.1993

[6]The Last Li's Houseboat disappearing. [RE/OL]. 1 Sept. 2016. http://mini.eastday.com/a/160901111337191.html 